\title{
ESTUDOS SOBRE O REGIME DISCIPLINAR DIFERENCIADO (RDD) PAUTADOS NO ENTENDIMENTO INTERNACIONAL E NOS DIREITOS HUMANOS
}

\author{
STUDIES ABOUUT THE DIFFERENTIATED DISCIPLINARY REGIME GUIDED \\ IN INTERNATIONAL UNDERSTANDING AND HUMAN RIGHTS
}

\author{
${ }^{1}$ Fernanda Eloise Schmidt Ferreira Feguri \\ ${ }^{2}$ Roberto Feguri
}

\section{RESUMO}

O trabalho tem como escopo analisar o Regime Disciplinar Diferenciado (RDD) sob a ótica dos direitos humanos, verificando sua aplicação dentro do cenário brasileiro, bem como trazendo suas consequências e o posicionamento internacional das Cortes e Organizações acerca de sua aplicabilidade. Inicialmente a pesquisa traz um breve recorte histórico do surgimento de tal regime, para então demonstrar suas consequências àqueles que ao isolamento celular prolongado e rigoroso se submetem. Todo o trabalho sedimenta-se na análise da aplicação do Regime Disciplinar Diferenciado (RDD) em face dos princípios da dignidade da pessoa humana e da humanidade das penas. Analisa também o Regime Disciplinar Diferenciado diante do estudo das funções das penas, enaltecendo apenas seu conteúdo retributivo, e descartando possibilidades de ressocialização de egressos para os presos, o que causa ou contribui significativamente para um processo de exclusão social.

Palavras-chave: Regime disciplinar diferenciado, Direitos humanos, Brasil, Posicionamento internacional, Ressocialização, Exclusão

\begin{abstract}
The work has the objective to analyze the Differentiated Disciplinary Regime from the perspective of human rights, checking their application in the Brazilian scenario, as well as bringing its consequences and the international positioning of the Courts and organizations about its applicability. Initially, the research brings a brief historical view of the emergence of such a system and then shows its consequences to those with prolonged and strict solitary confinement are submit. The whole work settles on the analysis of the application of Differentiated Disciplinary Regime face the principles of human dignity and humanity of penalties. It also analyzes the Differentiated Disciplinary Regime on the study of the functions of feathers, only praising his retributive content and discarding rehabilitation opportunities for graduates for prisoners, which causes or contributes significantly to the process of social exclusion.
\end{abstract}

Keywords: Cell isolation, Human rights, Brazil, International positioning, esocialization, Exclusion

\footnotetext{
${ }^{1}$ Doutora em Sistema Constitucional de Garantia de Direitos pelo Instituição Toledo de Ensino - ITE, Bauru - SP (Brasil). E-mail: fesferreira@uol.com.br

${ }^{2}$ Mestre em Sistema Constitucional de Garantia de Direitos pelo Instituição Toledo de Ensino - ITE, Bauru - SP (Brasil). Professor da Faculdade do Norte Novo do Paraná - FACNOPAR, Apucarana - PR (Brasil).

E-mail: roberto.feguri@uol.com.br
} 


\section{INTRODUÇÃO}

Este trabalho pretende fazer uma análise sobre a aplicabilidade do Regime Disciplinar Diferenciado (RDD) à luz dos direitos humanos, não somente abarcados pela Constituição Federal de 1988 como também sedimentados por diretrizes internacionais advindas, não apenas de Tratados e Convenções dos quais o Brasil é signatário, mas também de pareceres de Cortes e Organizações Internacionais, analisando tal regime em face dos princípios da dignidade da pessoa humana e da humanidade das penas.

O interesse nesta abordagem surge em decorrência de que nem mesmo a pena privativa de liberdade pode afastar-se de princípios basilares do Direito, que garantem a vida digna aos indivíduos, mesmo àqueles cerceados de liberdade de locomoção em razão de prisão.

Isto porque é direito do ser humano a convivência com seus pares. Pois seus valores são construídos a partir de experiências sociais. Diante disso, resta indagar se o isolamento celular rigoroso, prolongado respeita o princípio da dignidade da pessoa humana, com previsão constitucional e também em pactos e posicionamentos internacionais, como se verá.

Analisar-se-á também o Regime Disciplinar Diferenciado (RDD) em face do princípio da humanidade das penas, princípio basilar de todo o sistema punitivo. Por ele entende-se que a pena deverá abrigar em seu conteúdo a racionalidade e proporcionalidade. Ou seja, deverá ser racional e proporcional ao dano causado ao bem jurídico protegido. Além disso, deste princípio deriva a ciência que de a sanção aplicada não poderá ignorar a condição de pessoa humana do indivíduo privado de sua liberdade.

Destarte, insta estudar o Regime Disciplinar Diferenciado (RDD) e suas consequências à luz dos direitos humanos e das finalidades das penas, com enfoque na ressocialização do reeducando e afastamento da ideia de exclusão.

Considerando-se que a pena deve cumprir suas funções, ao aplicá-la, é imperioso separar o indivíduo do fato criminoso, devendo a conduta ser punida. Não se pode, contudo, desejar que esta punição transforme o indivíduo em res, em objeto, sem a dignidade que cerceia todo e qualquer ser humano, mesmo aqueles que delinquiram. 


\section{HISTÓRICO DA APLICAÇÃO DA PENA DE PRISÃO E DOS SISTEMAS PRISONAIS}

Iniciando o tema, guarda cabimento fazer um breve relato histórico da pena de prisão e dos sistemas prisionais, vez que não se pode olvidar que a questão do isolamento celular está ligada diretamente ao modelo de sistema prisional adotado por um ou outro Estado. Dessa forma, o entendimento do isolamento celular passa pela formação dos sistemas prisionais e sua evolução. Compreender que a pena privativa de liberdade e todas as suas peculiaridades fazem parte de um contexto histórico, cultural e social (em constante evolução) é o primeiro passo a se dar na tentativa de se entender o isolamento celular desde seu nascimento, sua evolução e variedades de regimes, até as suas consequências para o indivíduo privado de liberdade.

É de conhecimento geral que a história das penas sempre foi permeada por abusos, experiências mal sucedidas e desproporcionalidade. Ao se pensar nos suplícios e penas capitais aplicadas na Antiguidade e Idade Média, por exemplo, pode-se perceber que o ser humano ainda consegue extrapolar qualquer conceito de crueldade, quando se trata de punir aqueles que violam as regras de uma sociedade utopicamente pensada como homogênea.

Desde o surgimento da pena privativa de liberdade, grande parcela dos abusos cometidos aos indivíduos condenados foi coibida. Contudo, ainda hoje, pode-se dizer que entre a realidade do cárcere e a função da pena privativa de liberdade existe um abismo que muitas vezes se mostra intransponível.

É notório o fato de que o sistema prisional, sobretudo em termos pátrios, cada vez mais vem se tornando um ambiente propício para o crescimento da violência e para a violação de inúmeros direitos humanos, há tempos e com muitos esforços conquistados.

Problemas como a superlotação carcerária, precárias condições de higiene e estrutura dos presídios apenas revelam a ponta de um iceberg que tem suas bases ligadas à frágil capacidade estatal de lidar com o tema "cárcere".

A prisão aperfeiçoa o crime e, do lado oposto, falha em proporcionar a ressocialização, facilitando a reincidência, ocasionando revolta e opressão. Obviamente que não é apenas a prisão que tem o condão de marginalizar. A própria estrutura da sociedade, com todas as suas disparidades, tem contribuído para que a criminalidade cresça e tome proporções assustadoras. 
Todavia, no que toca à prisão, o maior desafio está em se criar condições favoráveis para a ressocialização e reinserção social, preocupações que desde o início do surgimento da pena privativa de liberdade estiveram em foco, tanto que, como preconizou Foucault (2009, p.

237), há mais de 150 anos, existem sete máximas universais para uma boa condição penitenciária, quais sejam:

\begin{abstract}
1) A detenção penal deve ter por função essencial a transformação do comportamento do indivíduo; 2) Os detentos devem ser isolados ou pelo menos repartidos de acordo com a gravidade penal de seu ato, mas principalmente segundo sua idade, suas disposições, as técnicas de correção que se pretende utilizar com eles, as fases de sua transformação; 3) As penas, cujo desenrolar deve poder ser modificado segundo a individualidade dos detentos, os resultados obtidos, os progressos ou as recaídas; 4) $\mathrm{O}$ trabalho deve ser uma das peças essenciais da transformação e da socialização progressiva dos detentos; 5) A educação do detento é, por parte do poder público, ao mesmo tempo uma precaução indispensável no interesse da sociedade e uma obrigação para com o detento; 6) $\mathrm{O}$ regime da prisão deve ser, pelo menos em parte, controlado e assumido por um pessoal especializado que possua as capacidades morais e técnicas de zelar pela boa formação dos indivíduos; 7) $\mathrm{O}$ encarceramento deve ser acompanhado de medidas de controle e de assistência até a readaptação definitiva do antigo detento.
\end{abstract}

Em termos concretos não se pode afirmar que houve uma evolução da prisão, mas inúmeras reformas, transformações desta forma de punição. E, infelizmente, ainda para a sociedade atual a prisão se revela como um mal necessário, uma "solução detestável de que não se pode abrir mão" (FOUCALT, 2009, p. 157).

Ao final do século XVIII e início do século XIX, começou-se a discutir o sistema penitenciário e as formas de reclusão dos indivíduos de forma intensa. Justamente neste período é que surgem os primeiros modelos correcionais em alguns presídios, como o da Filadélfia e o de Alburn, em Nova York (OLIVEIRA, 2010).

A privação da liberdade neste momento histórico foi certamente a maior inovação trazida neste período. O indivíduo seria punido com a perda da sua liberdade por certo período de tempo, o qual se relacionava (e ainda hoje se relaciona) com a gravidade do delito cometido.

O tempo, portanto, é o quantificador, é o elemento que impõe a reclusão por um período julgado como proporcional para se reparar a conduta ilícita praticada pelo agente. Note-se bem: apenas o tempo teria o poder de reparar o mal causado para a sociedade. Indubitavelmente uma ideia minimalista e utópica que, hodiernamente, ainda se aplica.

Além da questão do tempo como quantificador, o isolamento dos presos em células também foi elemento reformador do sistema penitenciário desta época. Como bem relata Foucault (2009, p. 199): 
[...] o preso deveria ser isolado do mundo exterior, a tudo o que motivou a infração, às cumplicidades que o facilitaram, e dos outros detentos, a fim de evitar qualquer tipo de complô e revolta. A pena deveria ser individual e individualizante, justificando assim o isolamento do encarcerado de qualquer outra pessoa.

O sistema filadélfico ou pensilvânico é exemplo do início do entendimento de que o isolamento celular poderia ser positivo para a reabilitação do preso. De acordo com Geraldo Ribeiro de Sá, adotado na Filadélfia, a principal característica deste sistema encontrava-se na reclusão total do preso, ou seja, no isolamento do indivíduo por todo o período da sua condenação (1996 apud OLIVEIRA, 2010).

Entende Bitencourt (2003) que o início deste sistema teve influência das sociedades integradas por Quacres e os mais respeitáveis cidadãos da Filadélfia, tendo como finalidade reformular as prisões. Segundo Georg Rusche e Otto Kirchheimer, "tal modelo se baseava nos princípios dos Quaker, que defendiam a ideia de que a religião era a única e suficiente base da educação, assim a reclusão dos presos aliado a leitura da bíblia, único objeto permitido dentro das celas, poderia levá-lo a uma reflexão e ao arrependimento de seus pecados" (2004 apud OLIVEIRA, 2010).

No sistema filadélfico o condenado era mantido isolado, não tinha direito a receber visitas e nem mesmo podia trabalhar. Era baseado no completo e diuturno isolamento celular (MESQUITA JÚNIOR, 1999, p. 185). Em verdade, os reclusos deveriam apenas se dedicar à instrução religiosa. Praticamente não havia banho de sol e a leitura da Bíblia era obrigatória para se conseguir o arrependimento dos encarcerados. A esse respeito ensina Greco (2005, p. 173):

\footnotetext{
No sistema pensilvânico ou de Filadéfia, também conhecido como celular, o preso era recolhido à sua cela, isolado dos demais, não podendo trabalhar ou mesmo receber visitas, sendo estimulados ao arrependimento pela leitura da Bíblia. Os únicos contatos que tinham com o mundo exterior consistiam nas visitas constantemente empreendidas pelos oficiais encarregados das prisões, ou pelos representantes da sociedade de ajuda aos presos.
}

De acordo com Álvaro Mayrink da Costa (1998, p. 1.455), neste sistema, baseado em isolamento celular, aos condenados não era permitido à saída da cela em nenhum momento, sendo que somente depois de decorridos alguns anos de sua criação é que o trabalho foi autorizado, porém ainda na cela.

Esse sistema surgiu pelo clamor da sociedade da Filadélfia e da Pensilvânia para se enfrentar o fracasso das prisões da época, assim, inspiradas nos quaqueiros, pediam por um novo modelo prisional baseado na separação dos indivíduos. 
Relata Bitencourt (2003) que as principais características do sistema filadélfico estava no isolamento celular, na obrigação estrita do silêncio, na meditação e na oração. $O$ sistema filadélfico reduzia os gastos com a vigilância e a segregação individual impedia a possibilidade de introduzir uma organização do tipo industrial nas prisões.

Mais adiante, outro precursor do isolamento celular surgiu com o denominado sistema auburniano criado em resposta às críticas proclamadas no sistema filadélfico. Em decorrência de resultados extremamente insatisfatórios com o sistema filadélfico, foi proposta a construção, no interior do estado de Nova York, na cidade de Auburn, do sistema que se iniciou em 1821, daí o nome sistema auburniano (OLIVEIRA, 2010).

Uma parte deste presídio servia ao regime de isolamento, e os prisioneiros, segundo Bitencourt (2004, p. 70,) eram divididos em três categorias:
1) A primeira era composta pelos mais velhos e persistentes delinquentes, aos quais se destinou o isolamento contínuo;2) $\mathrm{Na}$ segunda situavam-se os menos incorrigíveis, que somente eram destinados às celas de isolamento três dias na semana e tinham permissão para trabalhar; 3) A terceira categoria era integrada pelos que davam maiores esperança de serem corrigidos. A estes somente era imposto o isolamento noturno, permitindo-lhes trabalhar juntos durante o dia, ou sendo destinados às celas individuais um dia na semana.

O surgimento deste regime não se deu somente em decorrência da ânsia em se reestruturar o sistema filadélfico que vigorava até então, mas havia também uma conjectura histórico-política na época que pretendia trazer mudanças no sistema prisional, como bem aponta Moura (2007, p. 05):

\footnotetext{
Na primeira metade do século XVIII, a importação de escravos restringia-se cada vez mais devido a uma nova legislação imposta pelo governo das Treze Colônias, enquanto que a conquista de novos territórios e a rápida e crescente industrialização produziam um vazio no mercado de trabalho, que não conseguia ser suprido apenas pelos índices de natalidade e de imigração. Desta forma, o sistema auburniano surgiu como forma de adequar à mão de obra penitenciária aos intentos do sistema capitalista, submetendo o recluso ao seu regime político-econômico, aproveitando-o como força produtiva.
}

Da mesma forma, os reclusos serviam à classe dominante, no sentido do aproveitamento de sua força produtiva, sendo esta utilizada sem nenhuma forma de recompensa para os presos. Assim, o sistema auburniano não foi apenas uma consequência lógica da falência do filadélfico em virtude da falta de humanidade deste, mas, especialmente, este sistema surge em virtude de uma conjectura histórica, no que tange às transformações oriundas do mercado de trabalho. 
Tanto o sistema auburniano quanto o regime da Filadélfia (pensilvânico), na última fase, proíbem a comunicação com o exterior e embasam sua eficácia no trabalho (LYRA, 1942, p. 90).

Bornin (2011) explica que, enquanto o sistema filadélfico tinha por escopo a transformação do criminoso em um homem de bem por meio do arrependimento, o sistema auburniano pretendia condicionar o apenado pelo trabalho, disciplina e mutismo. Obviamente que ambos mais contribuíram para a degeneração do que para a reabilitação dos indivíduos.

Esse recorte serve como base de entendimento de como e porquê surgiu o isolamento celular dentro do sistema de execução da pena privativa de liberdade. Mais adiante se verá se como o isolamento celular ainda é utilizado no ordenamento penal pátrio e em quais situações, bem como se demonstrará quais suas consequências e se em sua aplicação há violação de direitos humanos fundamentais.

Mas, diante do breve histórico apresentado acima, pode-se concluir que, o Regime Disciplinar Diferenciado (RDD), com finalidade meramente retributiva, assemelha-se aos sistemas primitivos da Filadélfia (ou pensilvânico) e auburniano. Leva-se apenas em consideração que o reeducando deve recolher-se em sua cela, isolado dos demais, em absoluto e enlouquecedor silêncio. Há que se lembrar que os sistemas mencionados acima foram duramente criticados, pois impossibilitavam a ressocialização dos condenados. Assim, seria injustificável um retrocesso, retornando-se a um modelo deveras assemelhado aos mais primitivos, cujas consequências desastrosas a própria história nos remete.

\section{SOBRE O ISOLAMENTO CELULAR NA ATUALIDADE E A APLICAÇÃO DO REGIME DISCIPLINAR DIFERENCIADO (RDD)}

Por muitos anos o Brasil não vem investindo no sistema carcerário, acreditando que o problema das prisões se restringia aos presídios, não ultrapassando suas muralhas. Essa omissão, como bem adverte Porto (2007, p. 59), culminou por falir as técnicas aplicadas às penitenciárias brasileiras e, ainda, trouxe "como consequência a perda do controle sobre a população carcerária e o crescimento de organizações de facções criminosas".

Em conformidade com Fontes e Filizzola (2008, p. 05), o sistema carcerário do país foi nos últimos anos "relegado pela administração e tratado com absoluto desprezo". 
Segundo os aludidos autores, não há no sistema penitenciário do país respeito a diversos direitos fundamentais dos presos, tais como a honra, a imagem, a integridade física, nem mesmo oportunidade para que os apenados trabalhem ou estudem enquanto cumprem suas penas, atividades estas capazes de propiciar a ressocialização, já que permitem que o indivíduo mantenha de certa forma o convívio com a sociedade.

Como bem argumenta Gomes (2006, p. 13):

[...] apostar que a solução para o problema da violência seria a construção de presídios foi um equívoco, pois a violência não diminuiu, e dentro dos presídios nasceram as organizações criminosas brasileiras, que facilmente corrompem seus agentes, extremamente mal remunerados.

Para o autor, os presídios brasileiros ensinam novas e modernas técnicas de se servir ao crime, não havendo atualmente ilusão de ressocialização do preso. Porém ao menos se espera que o sistema prisional não dessocialize, ou seja, se não ressocializa, ao menos não piore a situação daqueles que o adentram.

Nesse contexto, Basileu (1942, p. 102) relata que se deixou influenciar o legislador brasileiro de 1940 pelo movimento anti-celular de que é legenda a famosa frase de Ferri, sempre repetida: "A cela é uma das aberrações do século XIX".

Para o referido autor (BASILEU, 1942, p. 102), essa manifestação era referente aos horrores da segregação celular, tal como acontecia no sistema de Filadélfia ou pensilvânico.

O isolamento celular tinha por finalidade segregar o indivíduo de outros que seriam mais pervertidos do que ele, poupando-o da convivência dos maus elementos e, por conseguinte, não haveria influencia do mal sobre ele.

Ocorre que o que se observou com o isolamento foi a transformação do apenado numa criatura fora da substância humana, diferente dos homens comuns, não regenerado, mas gravemente prejudicado em sua saúde, do corpo e do espírito, pressuposto indispensável à ressocialização. Acerca disso Basileu (1942, p. 102) entende:

Realmente, a cela, utilizada com esse rigor, constituía uma demonstração de impiedade, e bem se compreende o movimento filantrópico de reação que se lhe opôs. Já no sistema de Auburn passou a ser o que na verdade deve ser: o dormitório do recluso, em que ele, subtraído à promiscuidade nefasta, permanece apenas de noite segregado, após o labor em comum durante o dia. E assim continuou a ser a cela entendida no regime progressivo ou irlandês, com a restrição de que foi julgado necessário um inicial período, não pequeno, de isolamento absoluto. 
O fato é que o isolamento celular não deve ser a regra, quando aceito pelo ordenamento, mas a exceção, posto que a segregação absoluta por longo período de tempo somente tem por finalidade o castigo do apenado.

Concernente a isso Basileu (1942, p. 103) salienta que:

$\mathrm{O}$ moderno direito penal foge cada vez mais à antiga preocupação expiatória e punitiva. Independentemente, porém, de tal consideração, mesmo para aqueles que insistem em ver na pena a retribuição do mal pelo mal, ainda se justifica essa tendência a evitar a cela.

A mesma tendência é seguida pelo Código Penal italiano, que mesmo apreciando o caráter aflitivo da pena, prima pela redução do emprego do isolamento celular. Pondera Basileu (1942, p. 103):

Acreditava-se que a solidão forçaria o homem à meditação e a um recolhimento quase místico, mas teve-se de reconhecer que ela reforçava as tendências antissociais do condenado, tornando mais penosa e mais difícil a sua readaptação à vida social.

De fato, atualmente a tendência mundial é pela abolição do isolamento celular. Entretanto, ainda hoje existe a possibilidade de utilização deste sistema nas seguintes hipóteses:

\begin{abstract}
1) A separação dos internos em celas individuais durante a noite é a melhor resposta aos problemas que se originam ao encarcerar-se um grupo de pessoas. Neste sentido, o Congresso Penitenciário de Praga, celebrado em 1930, apesar de combater o regime filadélfico, considerava a separação individual durante a noite, elemento essencial de uma administração moderna. Também as regras mínimas de Genebra (art. 9, inciso I) recomendam que as celas destinadas ao isolamento noturno não devem ser ocupadas por mais de um recluso;2) $\mathrm{O}$ isolamento celular serve desde que não o convertam em meio de lesar a dignidade humana ou em simples tortura; 3 ) Dentro de certas condições de legalidade e sem partir da hipótese da incorrigibilidade, o regime celular também se aplica aos delinquentes perigosos (psicopatas de periculosidade extrema e com alto grau de nocividade); 4)Existem correntes favoráveis à aplicação do isolamento celular para o caso das penas privativas de liberdade de curta duração (BITENCOURT, 2004, p. 67).
\end{abstract}

Em se tratando de isolamento celular no cenário brasileiro, também não se pode deixar de citar o Regime Disciplinar Diferenciado (RDD). Entende-se o Regime Disciplinar Diferenciado (RDD) como um instrumento imposto pelo Estado para executar o cumprimento da pena privativa de liberdade de forma mais rigorosa que o modo convencional.

Originalmente, a Lei de Execução Penal (LEP) de 1984 não comportava tal regime, sendo este criado pela Resolução nº. 26 de 2001 da Secretaria de Administração Penitenciária de São Paulo. Posteriormente, incorporou-se à Lei de Execução Penal (LEP), através da transformação desta Resolução em Lei Federal (Lei nº. 10.792/03). 
Assim, O Regime Disciplinar Diferenciado (RDD) é entendido como um tipo de sanção, regulada através do artigo 53, inc. V, da Lei de Execução Penal, sendo suas hipóteses de cabimento previstas no artigo 52 do mesmo diploma, o que se abordará no próximo item.

Sua aplicação teria por intuito, em tese, atingir aqueles criminosos considerados de alta periculosidade, cujas práticas criminosas são extremamente nocivas à sociedade, bem como, aqueles que possuem grande probabilidade de novamente praticarem os mesmos crimes (artigo 172 da Lei de Execução Penal).

Segundo explica D’Agostino (2006), no Regime Disciplinar Diferenciado (RDD) o preso é mantido em uma cela individual por até 360 dias. Se ele cometer nova infração, a punição poderá voltar a ocorrer, até o limite de um sexto da pena.

No período de cumprimento da pena em Regime Disciplinar Diferenciado (RDD), o preso tem direito a duas visitas semanais de duas pessoas, sem contar as crianças, com duração de duas horas e igual período diário de banho de sol (artigo 52, inciso III, da Lei de Execução Penal). (Contudo, insta anotar que, na prática, tais direitos revelam interpretações bem limitadas; nem sempre garantidos, de acordo com a forma legalmente prevista.)

Mirabete (2004, p. 119) entende que o Regime Disciplinar Diferenciado (RDD):

(...) não constitui um regime de cumprimento de pena em acréscimo aos regimes fechado, semiaberto e aberto, nem uma nova modalidade de prisão provisória, mas sim um novo regime de disciplina carcerária especial, caracterizado por maior grau de isolamento do preso e de restrições ao contato com o mundo exterior.

Nota-se, portanto, ser o Regime Disciplinar Diferenciado (RDD) uma forma completamente diferenciada de prisão, não se enquadrando nas outras modalidades de regimes vistos anteriormente, sendo bem mais rigoroso em sua essência, já que isola quase que completamente o detento da sociedade e, por conseguinte, de modos de ressocialização.

Luisi (2003), remetendo-se a este regime afirma que ele encontra sua inspiração nas solitárias e nos suplícios, ao passo em que relata não ter este regime surgido simplesmente como mais uma das criações iluministas acerca da punição; mas inquestionavelmente sua gênese remonta aos antigos modelos de tortura física e psicológica adotados em outrora, em diversas nações, inclusive no Brasil.

Nesse compasso, o advento da "legalização" do Regime Disciplinar Diferenciado (RDD) não foi uma novidade, sobretudo ao analisar a constante atuação legislativa que se posiciona pelo direito penal do inimigo sustentada pelos clamores populares de vingança com vestes de justiça; tratamento degradante mascarado de pena. É o que pondera Hassemer (1993, p. 86): 


\begin{abstract}
Existe uma tendência do legislador em termos de política criminal moderna em utilizar uma reação simbólica, em adotar um Direito Penal simbólico. Quero dizer com isso, que os peritos nessas questões sabem que os instrumentos utilizados pelo Direito Penal não são aptos para lutar efetiva e eficientemente contra a criminalidade real. Isso quer dizer que os instrumentos utilizados pelo Direito Penal são ineptos para combater a realidade criminal. Por exemplo: aumentar as penas, não tem nenhum sentido empiricamente. O legislador - que sabe que a política adotada é ineficaz - faz de conta que está inquieto, preocupado e que reage imediatamente ao grande problema da criminalidade. É a isso que eu chamo de 'reação simbólica' que, em razão de sua ineficácia, com o tempo a população percebe que se trata de uma política desonesta, de uma reação puramente simbólica, que acaba se refletindo no próprio Direito Penal como meio de controle social.
\end{abstract}

Em suma, o legislador simulando estar atento às necessidades sociais, pauta-se numa atividade legiferante cheia de engodos, e cria uma forma simbólica de Direito Penal, pautado simplesmente no aumento de penas e rigorismo sancionador, como é o caso do Regime Disciplinar Diferenciado (RDD) e o isolamento celular impetrado por sua aplicação, não levando em conta outros aspectos que mais precisamente conseguiriam atenuar a criminalidade.

A natureza jurídica deste regime é administrativa, pois se aplica aos presos em regime fechado, os quais cumprem pena de reclusão, cujo comportamento é considerado perigoso, sendo tidos como fomentadores de indisciplina no interior dos presídios, contribuindo para rebeliões ou para o comando de outros crimes graves, inclusive fora da prisão.

O Regime Disciplinar Diferenciado (RDD) pode ser visto, por conseguinte, como um mecanismo inabilitador oriundo da sanção penal, o qual garante o efetivo isolamento dos indivíduos, dificultando o seu rompimento com a rede do sistema, gerando deterioração físico-psíquica nos detentos, em razão do isolamento celular, que, para Foucault (2009, p. 201), nada mais é que um "sepulcro provisório".

Em verdade, o que se pode enfatizar acerca do Regime Disciplinar Diferenciado (RDD) é que ele busca a dominação dos indivíduos através de imposições ritmadas pela disciplina e rigidez. Assim, tenta impor aos condenados uma forma de organização que servirá não para sua ressocialização, mas, sobretudo, para atender melhor os interesses dos grupos sociais dominantes, causando ou contribuindo para o processo de exclusão do egresso.

As consequências do isolamento rigoroso, como no caso do Regime Disciplinar Diferenciado (RDD), sempre foram extremamente desastrosas: 
[...] o isolamento se converta na pior tortura, com efeitos mais dolorosos que os que o castigo físico podia produzir, sem que seus danos fossem evidentes e sem que aparecessem no corpo do condenado. [...] a prisão celular é desumana porque elimina ou atrofia o instinto social, já fortemente atrofiado nos criminosos e porque torna inevitável entre os presos à loucura ou a extenuação (BITENCOURT, 2004, p. $65)$.

O sistema celular debilita socialmente o indivíduo, não dando espaço para sua reinserção na sociedade. Fomenta a falta de empatia e solidariedade com o outro, pois impede o contato humano do indivíduo enclausurado com seus pares.

Argumentam Adorno e Bordini(1991, p. 123) que o isolamento é a forma "mais acentuada de privação da liberdade na prisão, representando uma rejeição moral deliberada pela comunidade". Embora seja defendido por parte da equipe dirigente como medida terapêutica, "para o preso significa punição que agrava sua angústia e o sofrimento que vem arrastando por passagens anteriores nos estabelecimentos penais".

De acordo com Goffman (1974), o isolamento na prisão produz no indivíduo a sensação de perdas pessoais, haja vista que o preso passa por um processo de descaracterização de sua identidade adquirida anteriormente nas relações com a família, amigos e instituições religiosas, educacionais, profissionais.

Tendo em vista tais acepções, tradicionalmente, órgãos como a Anistia Internacional e a Organização das Nações Unidas (ONU) consideram como tortura os maus tratos e a violência física e psíquica, que também se atrela ao isolamento celular, sobretudo ao prolongado.

Para tanto é preciso estender-se o conceito de tortura, como bem o fazem Viñar e Viñar (1992, p. 59):

[...] mais do que formas e técnicas da violência, o que conta é o tempo infinito, o horror sem limite, as condições de isolamento, a estranheza, a solidão, assim como a sucessão de imagens fragmentárias e contraditórias que conduzem à loucura descrita na síndrome de privação sensorial. Sendo assim, tortura seria todo dispositivo intencional, quaisquer que sejam os meios utilizados, engendrada com a finalidade de destruir as crenças e convicções da vítima para privá-la da constelação identificatória que a constitui como sujeito. Este dispositivo é aplicado pelos agentes de um sistema de poder totalitário e é destinado à imobilização pelo medo da sociedade governada.

Dostoiewski (apud DOTTI, 1998, p.113) relatando as suas memórias do cárcere, na intensidade dos maiores sofrimentos, o imortal escritor russo, descreveu que:

[...] o famoso sistema celular só atinge, estou disto convencido, um fim enganador, aparente. Suga a seiva vital do indivíduo, enfraquece-lhe a alma, amesquinha-o, aterroriza-o, e, no fim, apresentando-o como modelo de correção, de arrependimento, uma múmia moralmente dissecada e semilouca. 
O que se pode observar é que mesmo com as consequências que o isolamento total produz nos indivíduos, este não é inteiramente rechaçado, como se pôde observar. Neste sistema não se nota a mínima intenção de se fomentar a reabilitação do preso, a única coisa que se pode vislumbrar certamente é uma grande tendência de dominação e controle de alguns em detrimento de outros. Tal sistema prega, como se pode concluir, o exercício permanente da tortura, escravizando a mente e aniquilando a dignidade do ser humano.

\section{POSICIONAMENTO INTERNACIONAL ACERCA DO ISOLAMENTO CELULAR RIGOROSO}

A partir da segunda metade do século XX, o tema "direitos humanos" ganhou contornos extremamente relevantes na seara do Direito Internacional, sendo que toda essa importância adveio de um processo lento e paulatino de internacionalização e universalização desses direitos.

Em decorrência desse processo de internacionalização e universalização, o conceito de soberania dos Estados, antes absoluto, torna-se mais brando, haja vista que hodiernamente os Estados não são mais os únicos sujeitos de Direito Internacional, posto que os indivíduos passaram a ter meios para se protegerem contra de lesões de direitos que se encontram balizados e assegurados internacionalmente, inclusive em face de violações destes direitos produzidas pelos próprios Estados.

Trindade (2002, p. 31) a esse respeito leciona que:

[...] a titularidade jurídica internacional do ser humano, tal como a anteviam os chamados fundadores do direito internacional (o direito das gentes), é hoje uma realidade. No âmbito do Direito Internacional dos Direitos Humanos, nos sistemas europeu e interamericano de proteção - dotados de tribunais internacionais em operação -, se reconhece hoje, a par da personalidade jurídica, também a capacidade processual internacional (locusstandi in judicio) dos indivíduos. É este um desenvolvimento lógico, porquanto não se afigura razoável conceber direitos no plano internacional sem a correspondente capacidade processual de vindicá-los. Os indivíduos são efetivamente a verdadeira parte demandante no contencioso internacional dos direitos humanos.

Destarte, resgatar o valor da pessoa humana como cerne dos direitos humanos é primordial para se continuar evoluindo dentro desse sistema internacional de direitos humanos, pois como ensinou Arendt (apud LAFER, 1988, p. 166) a cidadania é a principal 
forma de se garantir o respeito pelos direitos dos indivíduos, já que é a materialização das medidas de proteção dos direitos humanos, de caráter universal e indivisível, pois:

[...] o primeiro direito humano, do qual derivam todos os demais, é o direito a ter direitos, direitos que a experiência totalitária mostrou que só podem ser exigidos através do acesso pleno à ordem jurídica que apenas a cidadania oferece.

No que concerne à característica de universalidade dos direitos humanos, caberá aos Estados respeitarem e promoverem tais direitos, abstraindo-se de "qualquer particularidade nacional ou regional e também das concepções próprias das diferentes culturas existentes" (GARCIA, 2005, p. 45). Assim, os Estados devem buscar a preservação dos valores pessoais e individuais de seus cidadãos de modo a proteger o bem-estar social, "objetivo que deveria ocupar o epicentro de qualquer estrutura de poder" (GARCIA, 2005, p. 47).

Diante disso, mesmo o indivíduo aprisionado, por sua condição de pessoa humana, não perde sua dignidade. Justamente por isso as Constituições do século XIX e as atuais proíbem penas cruéis e degradantes.

A dignidade da pessoa humana, bem como o princípio da humanidade das penas são elementos constantes na Constituição de 1988 (artigo 5º incisos III, XLIX e XLVII, alínea “e”) e em Tratados Internacionais ratificados pelo Brasil:

Igualmente a Convenção Americana de Direito Humanos determina no seu artigo $5^{\circ}$ referente ao direito à integridade pessoal que: "Ninguém será submetido às torturas, nem a penas ou tratos cruéis, desumanos ou degradantes. Toda pessoa privada de liberdade de ser tratada com o respeito devido à dignidade inerente ao ser humano" (VELLOSO, 2010, p. 04).

Também a Declaração Universal dos Direitos Humanos da Organização das Nações Unidas (ONU), em seu artigo $5^{\circ}$, determina: "ninguém será submetido à tortura nem a penas ou tratamentos cruéis, desumanos e degradantes".

Não obstante vale ressaltar, conforme Luisi (2003, p. 35):

[...] é preciso, no entanto, não esquecer que através da pena a sociedade responde às agressões que sofre com o cometimento de um delito. E, como decorrência não se pode deixar de enfatizar que o indeclinável respeito ao princípio da humanidade não deve obscurecer a natureza aflitiva da sanção penal.

Em outros termos, o supramencionado autor preconiza que o delito cometido deve ser punido, já que a sociedade é a principal ofendida quando um ilícito é praticado. Todavia, a sanção a este delito não deve ultrapassar a barreira imposta pela dignidade da pessoa humana e nem o princípio da dignidade das penas. Muito embora se saiba que a dignidade humana não 
é ilimitada, deve ser respeitada o máximo possível, dentro de cada contexto e caso concreto apresentado.

Portanto, defronte a tudo o que foi exposto, o isolamento celular rigoroso, a exemplo do Regime Disciplinar Diferenciado (RDD) brasileiro, viola claramente postulados de direitos humanos. Essa violação claramente se revela no caso do Regime Disciplinar Diferenciado (RDD), quando isola o condenado em cela individual por até 360 dias. Essa medida de isolamento celular deflagra o teor de humilhação ao preso submetido a este sistema, e deve receber o título de pena cruel e desumana. Sobre isso destacam Ferreira e Raya (2004, p. 273):

Nesse sentido, isolar uma pessoa durante 360 dias, limitando sua liberdade de movimentos, restringindo extremamente suas comunicações e seus vínculos com o exterior e endurecendo, em geral, todas as suas condições de vida,configura um tratamento degradante, que aumenta desnecessariamente a humilhação que já sofre uma pessoa submetida a uma pena privativa de liberdade, situação mais grave ainda em ambientes onde a realidade das prisões é lamentável, como é o caso brasileiro.

O rígido isolamento celular sob essa perspectiva demonstra uma restrição de direitos que não foram limitados por uma sentença penal condenatória, prejudicando sobremaneira a capacidade de se ressocializar o egresso. Beiras (apud FERREIRA; RAYA, 2004, p. 278) demonstra o que vem a ser tratamento degradante:

[...] há de entenderse como trato degradante aquel que essusceptible de crear em lãs víctimassentimientos de temor, de angustia y de inferioridadcapaces de humillarles, de envilecerles y de quebrantar, em su caso, su resistência física y moral.

A esse respeito, estabelecendo-se um comparativo com o Regime Disciplinar Diferenciado (RDD) pátrio, a Corte Interamericana de Direito Humanos posiciona-se no sentido de que o isolamento celular prolongado constitui-se tratamento cruel e desumano, que fere o princípio da humanidade das penas, albergado no artigo $5^{\circ}$ da Convenção Americana de Direito Humanos. Em meio dos julgados, elencam-se dois casos que se ligam ao tema ora discutido: o caso Velásquez Rodríguez contra o Estado de Honduras e o caso Castillo Petruzzi e outros contra o Estado do Peru.

Sobre o caso Velásquez Rodríguez contra o Estado de Honduras, que obteve sentença proferida em 29 de julho de 1988, pela Corte Interamericana de Direitos Humanos, restou consignado que o isolamento celular prolongado revela-se uma forma de tratamento desumano e cruel, lesivo à integridade psíquica e moral do preso; ferindo-se a dignidade humana e violando o artigo $5^{\circ}$ da mencionada Convenção. Nestes termos (CORTE INTERAMERICANA DE DIREITOS HUMANOS, 1988, p. 70): 


\begin{abstract}
"156. Además, elaislamiento prolongado y laincomunicación coactiva a los que se ve sometida lavíctimarepresentan, por símismos, formas de tratamiento cruel e inhumano, lesivas de laintegridad psíquica y moral de la persona y delderecho de todo detenido al respetodebido a ladignidadinherente al ser humano, lo que constituye, por su lado, laviolación de lãs disposiciones Del artículo 5 de laConvención que reconocenelderecho a laintegridadpersonal como sigue:

1. Toda persona tiene derecho a que se respete su integridad física, psíquica y moral.

2. Nadiedebe ser sometido a torturas ni a penas o tratos crueles, inhumanos o degradantes. Toda persona privada de libertad será tratada conelrespetodebido a ladignidadinherente al ser humano".
\end{abstract}

Já, no que se refere ao caso CastilloPetruzzi e outros contra o Estado do Peru, a Corte entendeu que o isolamento celular prolongado e a proibição de visitas também ferem o artigo da Convenção já supracitado, constituindo-se em pena atentatória à dignidade humana, considerando-se sobretudo que produz no ser humano graves efeitos, como perturbações psíquicas, efeitos psicológicos negativos e sofrimentos não só no corpo mas também no espírito. Nestes termos (CORTE INTERAMERICANA DE DIREITOS HUMANOS, p. 60):

"194. La Corte ha establecido que el "aislamiento prolongado y laincomunicación coactiva son, por símismos, tratamientoscrueles e inhumanos, lesivos de laintegridad psíquica y moral de la persona y delderecho al respeto de ladignidadinherente al ser humano.

195. La Corte ha dicho, también, que en "los términos del artículo 5.2 de laConvención toda persona privada de libertadtienederecho a viviren condiciones de detencióncompatiblesconsudignidadpersonal y el Estado debegarantizarleelderecho a la vida y a laintegridadpersonal. Enconsecuencia, el Estado, como responsable de losestablecimientos de detención, es el garante de estosderechos de losdetenidos". La incomunicación ha sido concebida como un instrumento excepcional por los graves efectos que tiene sobre eldetenido, pues "elaislamientodel mundo exterior produceencualquier persona sufrimientosmorales y perturbaciones psíquicas, la coloca en una situación de particular vulnerabilidad yacrecient[a] elriesgo de agresión y arbitrariedadenlascárceles".

No mesmo sentido, durante esta pesquisa, visualizou-se que nos Estados Unidos, recente relatório, divulgado em 16 de julho de 2014 , e intitulado Entombed: Isolation in the US Federal Prison System (Enclausurados: Isolamento no Sistema Prisional Federal dos Estados Unidos), revela as condições profundamente adversas que presos enfrentam numa penitenciária localizada próximo à cidade de Florence (em Colorado), conhecida como ADX Florence (AMNISTIA INTERNACIONAL, 27 jul. 2014).

O referido relatório expõe as consequências físicas e psicológicas do isolamento de presos em celas solitárias durante 22 a 24 horas por dia. As condições desumanas na ADX Florence já levaram alguns presos à auto-mutilação e até mesmo ao suicídio. Os reflexos do isolamento prolongado incluem a ansiedade, a depressão, a hipertensão, paranoia extrema, distorção da perceção e até psicose (AMNISTIA INTERNACIONAL, 17 jul. 2014). 
Segundo avalia a diretora do Programa Américas da Amnistia Internacional, Erika Guevara-Rosas, "É impossível exagerar o impacto devastador que longos períodos em prisão solitária podem ter na condição física e mental de um preso. Tal tratamento desumano é uma prática rotineira nos Estados Unidos e está em violação das leis internacionais" (AMNISTIA INTERNACIONAL, 17 jul. 2014).

Mas, insta anotar que há casos isolados, em que o Direito Internacional parece seguir na contra-mão dos direitos humanos, quando tribunais decidem no sentido de prolongar o isolamento celular.

Como num caso que se refere ao isolamento celular por longo período de tempo, e que foi bastante divulgado: o caso de Cesare Battisti, que além de ser condenado à prisão pérpetua, ainda foi condenado a seis meses de isolamento celular e privação de luz solar (PASSA PALAVRA, 2011), o que configura flagrante violação aos direitos humanos.

Afinal, como é possível, na Europa, no século XXI, um ser humano ser sujeitado a uma pena tão cruel?

Outro caso de exceção, que também vai contra o entendimento internacional é o caso de prisão de Anders Behring Breivik, autor dos atentados de 22 de julho de 2011, na Noruega. Ele passou algumas semanas em total isolamento. E ao tribunal de Oslo, que determinou tal medida, "parece razoável que ele seja mantido em completo isolamento devido ao risco de que ele e outros presos possam contatar cúmplices e destruir provas” (VEJA, 2011).

Nesse sentido, percebe-se que no que tange ao direito comparado, os tribunais e organizações internacionais, em sua maioria, concretizam a ideia abstrata da dignidade ao destacar que o isolamento prolongado e a incomunicação coativa representam, por si só, meios de tratamento cruel e desumano que contradizem a dignidade da pessoa humana. Sendo assim, é notório que a tensão entre o caráter abstrato e o caráter concreto da dignidade humana encontra sua resolução nos tribunais de justiça, ao passo em que faz parte da função de tais órgãos determinar, nos casos que examinam, o significado preciso do que é violação da dignidade humana (MONSALVE; ROMÁN, p. 96). Desse modo, o Regime Disciplinar Diferenciado (RDD) mostra-se como uma forma de tratamento que não pode ser justificada por necessidades de segurança ou qualquer outra razão.

Sabendo-se que a sanção penal tem por um de seus objetivos ressocializar o condenado para que este retorne a vida em comunidade, proporcionando condições para que o sentenciado, depois de ter cumprido sua pena, possa retornar para a sociedade e não mais 
cometer delitos, o isolamento celular revela-se na contramão do cumprimento de tais objetivos. Para Fragoso (1989, p. 07):

É perfeitamente óbvio que o sistema de encarceramento é incompatível com qualquer espécie de "tratamento", seja qual for o sentido que a ele se atribua. O simples fato de forçar uma pessoa a viver em isolamento, numa situação em que todas as decisões são tomadas para ela, não pode ser forma de treinamento para viver numa sociedade livre.

O autor preceitua que a prisão, assim como outras instituições como as escolas e igrejas, por exemplo, são instituições de controle social, sendo que os que dominam e têm poder tendem a abusar dele, em maior ou menor extensão. Obviamente que há prescrições legais de quais tratamentos são abusivos, além de posicionamentos nacionais e internacionais que demonstram como os detentos também possuem o direito à vida dentro de toda a dimensão que este direito pressupõe (dignidade, saúde, educação, integridade física, moral, psicológica etc.). Contudo, o abismo que se interpõe entre a teoria (prescrição legal) e a prática (realidade do cárcere) se torna cada vez mais intransponível.

O isolamento celular rigoroso e abusivo, como o Regime Disciplinar Diferenciado (RDD), por conseguinte, é a prisão dentro da própria prisão, o qual não provoca apenas o isolamento físico do apenado, mas, sobretudo, o isola de sua própria identidade e de uma possível ressocialização.

Apesar de parecer dicotômico falar em direitos humanos dos apenados, sobretudo por ser a prisão uma instituição propícia, por sua natureza, à despersonalização e repressão psicológica, a pena não deve ultrapassar limites considerados extremamente nocivos ao indivíduo. Nesta seara, o isolamento celular pautado na dignidade humana é justamente um limite que não deveria ser ultrapassado. Quando não se considera a razoabilidade e bom senso em sua aplicação, é mecanismo de tortura, instrumento de castigo que traz ao apenado somente degradação de sua identidade, não se convertendo em nenhum benefício, nem para o preso, muito menos para a sociedade.

\section{CONCLUSÃO}

Desde os tempos mais remotos, aqueles indivíduos que transgredissem as normas implementadas pela sociedade são punidos. Portanto, o início dos sistemas punitivos encontra-se ligado diametralmente à própria gênese da sociedade e, assim como esta última, os sistemas punitivos se desenvolveram, evoluindo de acordo com os anseios sociais. 
Contudo, o fato é que ainda hodiernamente o desejo de se punir o indivíduo transgressor conserva um resquício primitivo da pena vista apenas sob a égide da retribuição do mal causado por seu agente. Isto é: quem comete um ilícito deve sofrer um mal correspondente.

Em que pese o conhecimento geral de que atualmente não se deve admitir que a pena cumpra apenas a sua finalidade retributiva, devendo satisfazer o binômio retribuição e prevenção, bem como devendo esta primar pela ressocialização do apenado, infelizmente, ainda é possível observar muitos instrumentos de direito penal que possuem apenas o condão retributivo, caso do Regime Disciplinar Diferenciado (RDD) pátrio. O isolamento celular abusivo, rigoroso, quando não baseado na proporcinalidade, bom sendo e razoabilidade, converge-se numa punição degradante, mascarada de pena, contrária aos direitos humanos e princípios penais universalmente aceitos.

Observou-se que o fator que mais revela crueldade no Regime Disciplinar Diferenciado (RDD) é a capacidade deste de aniquilar qualquer interação social que o detento possa vir a ter.

O grande problema se encontra na própria natureza do Regime Disciplinar Diferenciado (RDD) e na função que lhe é atribuída pela sociedade. O isolamento celular cumpre uma função ideológica como expressão de castigo, esbaldando-se apenas no caráter retributivo e no caráter preventivo da pena. Além disso, o isolamento celular desproporcional, prolongado, apresenta-se como meio de tortura, ferindo a dignidade humana.

A sociedade, mesmo no atual patamar de evolução, ainda confunde a justiça com a vingança e o fato de ainda existir no ordenamento penal brasileiro a possibilidade de aplicação do isolamento celular desumano e prolongado, como no Regime Disciplinar Diferenciado (RDD), só comprova que, mais uma vez, essa confusão se perpetua. Os suplícios de hoje são modernos, com técnicas de crueldade camufladas pelo véu obscuro de uma pseudo justiça.

O Regime Disciplinar Diferenciado (RDD) mostra que novamente se está diante da pena como castigo, da pena que apenas quer servir como "exemplo", onde não só o corpo deve ser ferido, mas, sobretudo a alma, o espírito dos apenados, retirando-lhes toda e qualquer expressão da dignidade e da esperança.

O senso comum clama que não só o preso cumpra sua pena em regime superfechado e rigoroso, mas que também a cumpra da pior forma possível, sem a observância de direitos ou garantias fundamentais. Assim, a desumanidade no cumprimento da pena e a situação de 
degradação enfrentada por muitos detentos parece, aos olhos da sociedade, fazer parte da pena ou de seu cumprimento.

Tal entendimento não é corroborado pelos organismos internacionais de proteção aos direitos humanos, e, internamente, pela Constituição de 1988. Contudo, o afã de conter a onda de criminalidade, vista dentro e fora do sistema carcerário, faz com que o Estado crie ou recrie mecanismos teratológicos como o Regime Disciplinar Diferenciado (RDD), a fim de se tentar conter o clamor popular em busca de segurança. A previsão e a permissão de tal regime no Brasil somente atestam a ineficiência do nosso sistema prisional.

Em suma, o Estado pega um atalho conveniente para mascarar o problema da criminalidade, ao invés de agir no cerne da questão, transformando suas ações no sentido de dar estrutura básica para que seus cidadãos tenham dignidade e, por conseguinte, não tomem o caminho da marginalidade. Prefere empregar o Direito Penal como prima ratio, lamentavelmente.

\section{REFERÊNCIAS}

ADORNO, Sérgio; BORDINI, Eliana Bordinill. A socialização na delinquência: reincidentes penitenciários em São Paulo. Cadernos CERU, São Paulo, n. 3, Série 2, p. 113-147, 1991.

AMNISTIA INTERNACIONAL. Entombed: Isolation in the US Federal Prison System. Disponíve41 em: < http://www.amnistiainternacional.pt/files/Relatoriosvarios/Report_ENTOMBED_IsolationInTheUSfederalprisons ystem.pdf>. Acesso em: 27 jul. 2014.

Oito anos numa solitária: sistema prisional de máxima segurança nos

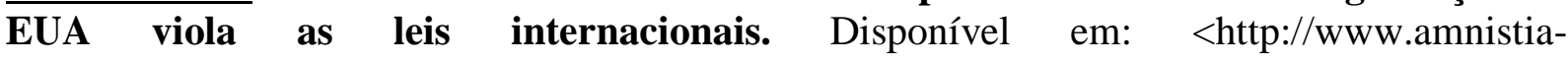
internacional.pt/index.php?option=com_content $\&$ view=article \&id=1752:2014-07-16-10-30-

37\&catid=35:noticias\&Itemid=23> . Acesso em: 17 jul. 2014.

BITENCOURT, Cezar Roberto. Falência da pena de prisão - causas e alternativas.3 ed. São Paulo: Saraiva, 2004.

Saraiva, 2003.

, Cezar Roberto. Tratado de direito penal: parte geral.8 ed. São Paulo:

BORNIN, Daniela Queila dos Santos. Presos, direito e sociedade: a procura da redescoberta da ressocialização na contemporaneidade. Dissertação (Mestrado) Instituição Toledo de Ensino. Bauru-São Paulo: Instituição Toledo de Ensino, 2011. 
CARVALHO, Salo de (Coord.). Críticas à execução penal. 2 ed. Rio de Janeiro: Lumen Juris, 2007.

CORTE INTERAMERICANA DE DERECHOS HUMANOS. Informe Anual de la Corte Interamericana de Derechos Humanos 1988. Disponível em: <http://www.corteidh.or.cr/docs/informes/1988.pdf>. Acesso em: 21 jun. 2014.

Caso CastilloPetruzzi y otros Vs. Peru. Sentencia de 30 de mayo de 1999. Disponível em: <http://www.corteidh.or.cr/docs/casos/articulos/seriec_52_esp.pdf >. Acesso em: 21 jun. 2014.

COSTA, Álvaro Mayrink da.Direito penal.6 ed. V. 1, t. 3., Rio de Janeiro: Forense, 1998.

D’Agostino, Rosanna. Projeto de lei na Câmara prevê endurecimento do RDD. Disponível em: <http://ultimainstancia.uol.com.br/noticia/31021.shtml> Acesso: 20 jun. 2014.

DOTTI, René Ariel. Bases e alternativas para o sistema de penas. São Paulo: RT, 1998.

FERREIRA, Fábio Félix; RAYA, Salvador Cutiño. Da inconstitucionalidade do isolamento em cela e do regime disciplinar diferenciado. Revista Brasileira de Ciências Criminais, v. 12, n. 49, p. 251- 290, jul./ago. 2004.

FONTES, Paulo Álvaro Chaves; FILIZZOLA, Ricardo Brandle. O regime disciplinar diferenciado é constitucional? Disponível em: http://www2.oabsp.org.br>. Acesso em: 25 mai. 2014.

FOUCAULT, Michel. Vigiar e punir. 37 ed. Petrópolis: Vozes, 2009.

FRAGOSO, Heleno Cláudio. Perda da liberdade - os direitos dos presos. Revista de Direito Penal, n. ${ }^{\circ}$ 29, 1989, p. 05 a 17.

GARCIA, Basileu. Regimes adequados ao cumprimento das penas de reclusão e detenção - estabelecimentos de prisão provisória. Revista da Faculdade de Direito, Universidade de São Paulo, [S.1.], v. 37, p. 100-117, jan. 1942. ISSN 2318-8235. Disponível em: <http://www.revistas.usp.br/rfdusp/article/view/65988/68599>. Acesso em: 20 jun. 2014.

GARCIA. Emerson. Proteção internacional dos Direitos Humanos: breves reflexões sobre os sistemas convencional e não-convencional. Rio de Janeiro: Lumen Iuris, 2005. GOFFMAN, Erving. Manicômios, prisões e conventos. São Paulo: Perspectiva, 1974.

GOMES, Luiz Flávio. RDD e regime de segurança máxima. Disponível em: <http:// jus2.uol.com.br/doutrina>. Acesso em: 26 mai. 2014.

GRECO, Rogério. Direito penal do equilíbrio. Niterói: Impetus, 2005.

HASSEMER, Winfried. Três temas de direito penal. Porto Alegre: Fundação Escola Superior do Ministério Público, 1993. 
LUISI, Luis. Os princípios constitucionais penais. 2 ed. rev. e aum. Porto Alegre: Sergio Antônio Fabris Editor, 2003.

LYRA, Roberto. Comentários ao código penal. Rio de Janeiro: Forense, 1942.

MESQUITA JÚNIOR, Sidio Rosa de. Manual de execução penal: teoria e prática. São Paulo: Atlas, 1999.

MIRABETE, Julio Fabbrini. Execução penal: comentários à Lei 7.210, de 11 de julho de 1984. 11 ed. São Paulo: Atlas, 2004.

MONSALVE, Viviana Bohórquez; ROMÁN, Javier Aguirre. As tensões da dignidade humana: conceituação e aplicação no direito internacional dos direitos humanos. Sur, Rev. int. direitos human. vol.6 n.11 São Paulo Dec. 2009.

MOURA, Maria Thereza Rocha de Assis. Notas sobre a Inconstitucionalidade da Lei 10.792/2003, que criou o Regime Disciplinar Diferenciado na Execução Penal. In: OLIVEIRA. Fernanda Amaral de. Os modelos penitenciários no século XIX. Disponível em: <http://www.ufjf.br/virtu/files/2010/05/artigo-6-a-1.pdf>. Acesso em: 25jun. 2014.

ORGANIZAÇÃO DAS NAÇÕES UNIDAS. Regras Mínimas para o Tratamento de Prisioneiros. Disponível em: <http://www.dhnet.org.br/direitos/sip/onu/fpena/lex52.htm>. Acesso em: 24 jun. 2014.

PASSA PALAVRA. O caso Cesare Battisti: o Brasil não pode ser cúmplice de uma sentença que implica tortura. Disponível em: <http://passapalavra.info/2011/01/34539>. Acesso em: 16 jul. 2014.

PORTO, Roberto. Crime organizado e sistema prisional. São Paulo, Atlas, 2007.

TRINDADE, Cançado. A personalidade e a capacidade jurídicas do indivíduo como sujeito do direito internacional. In: ANNONI, Danielle. (Coord.). Os novos conceitos do novo direito internacional: cidadania, democracia e Direitos Humanos. Rio de Janeiro: América Jurídica, 2002.

VEJA. Justiça norueguesa prolonga prisão e isolamento de Breivik. Disponível em:< http://veja.abril.com.br/noticia/internacional/justica-norueguesa-prolonga-prisao-eisolamento-de-anders-breivik>. Acesso em: 15 jul. 2014.

VELlOSO, Ricardo Ribeiro. O Tribunal Penal Internacional. Disponível em: < http://www.mundojurídico.adv.br>. Acesso em: 20 jun. 2014.

VIÑAR, Maren; VIÑAR, Marcelo. Exílio e tortura. São Paulo: Escuta, 1992. 